\title{
Laser Beam Welding of AA5052, AA5083, and AA6061 Aluminum Alloys
}

\author{
A. El-Batahgy ${ }^{1}$ and M. Kutsuna ${ }^{2}$ \\ ${ }^{1}$ Manufacturing Technology Department, Central Metallurgical Research and Development Institute, Cairo, Egypt \\ ${ }^{2}$ Advanced Laser Technology Research Center, Nagoya, Japan
}

Correspondence should be addressed to A. El-Batahgy, elbatahgy@yahoo.com

Received 10 July 2008; Revised 5 March 2009; Accepted 6 May 2009

Recommended by Rui Vilar

The present investigation was mainly concerned with characteristics of autogeneous laser butt welding of 2 mm thickness nonheat treatableAA5052-H12, AA5083-H12 and $2 \mathrm{~mm}, 3 \mathrm{~mm}$ thickness heat treatableAA6061-T6 aluminum alloys. The effect of laser welding parameters, surface cleaning, filler wire addition, and backing strip on quality of laser welded joints was clarified using $5 \mathrm{~kW} \mathrm{CO} 2$ laser machine. It was found that all the investigated alloys showed tendencies for porosity and solidification cracking, particularly, at high welding speed ( $\geq 4 \mathrm{~m} / \mathrm{min})$. Porosity was prevented by accurate cleaning of the base metal prior to welding and optimizing the flow rate of argon shielding gas. Solidification cracking was avoided through two different approaches. The first one is based on the addition of filler metal as reported in other research works. The other new approach is concerned with autogeneous welding using a backing strip from the same base metal, and this could be applicable in production. Preventing solidification cracking in both cases was related mainly to a considerable decrease in the stress concentration at the weld metal center as a result of improving the fusion zone profile. The implementation of the new approach could help in producing weldments with a better quality due to the absence of the filler metal, which is known as a source for hydrogen-related porosity. It can also have a positive economic aspect concerning the manufacturing cost since welding is done without the addition of filler metal. Not only quality and economic positive aspects could be achieved, but also high productivity is another feature since high quality autogeneous weldments were produced with high welding speed, $6 \mathrm{~m} / \mathrm{min}$. Hardness measurements and tensile test of AA6061 alloy welds indicated a remarkable softening of the fusion zone due to dissolution of the strengthening precipitates, and this was recovered by aging treatment after welding. For alloys AA5052 and AA5083, softening of the fusion zone due to the loss of its work-hardened condition was much less in comparison with AA6061 alloy.

Copyright (C) 2009 A. El-Batahgy and M. Kutsuna. This is an open access article distributed under the Creative Commons Attribution License, which permits unrestricted use, distribution, and reproduction in any medium, provided the original work is properly cited.

\section{Introduction}

Aluminum alloys have been widely used in different industrial applications such as tanks, pressure vessels, aerospace, and vehicles because of their high specific strength, heat conductivity, and good properties at low temperatures. The use of aluminum alloys within sheet metal processing particularly in the automotive and transportation sectors is increasing with the continuing drive to reduced weight and improved efficiency [1].

Both arc welding and electron beam welding have been mainly used as conventional welding processes for the aluminum alloys [2-4]. During the last two decades, significant and improved solutions for welding aluminum alloys were developed [5-8]. Although the use of highpower lasers for processing stainless steels and alloy steels has been extensively researched, studies on aluminum alloys are relatively limited. Previous studies have indicated porosity, excessive material loss, and solidification cracking as the most common problems encountered in the laser welding of aluminum alloys [9-12].

The incident beam reflection due to poor coupling between aluminum alloys and the laser beam is another major concern. Aluminum alloys absorb the laser more efficiently as the laser wavelength decreases. It has been reported that the Nd:YAG laser with a characteristic wavelength of $1.06 \mu \mathrm{m}$ provided better coupling with aluminum than the $\mathrm{CO}_{2}$ laser, which has a characteristic wavelength of $10.6 \mu \mathrm{m}$. 
Furthermore, the absorption of the laser beam increases drastically when a keyhole is formed due to multiple reflections of the beam in the keyhole [13]. Therefore, the $\mathrm{Nd}$ :YAG laser seems to be more attractive for the welding of aluminum alloys. The problem of the high reflectivity of aluminum alloys to the $\mathrm{CO}_{2}$ laser beam has been investigated with the aim of making use of the available higher power $\mathrm{CO}_{2}$ laser machines [14].

Recently, tremendous efforts have been made to clarify the fundamental laser weldability of different types of aluminum alloys using both Nd:YAG and $\mathrm{CO}_{2}$ lasers [1519]. It is pointed out that improvements in the laser weldability of a range of aluminum alloys are possible by increasing the power density of the focused spot, and this can be achieved through higher average powers, improved beam focusing system, and decreasing beam reflectivity on workpiece surface. The solidification cracking problem of laser welded aluminum alloys has been solved mainly through the addition of filler metals.

However, this field is far from being completed, and more investigations are required since there is an increasing considerable interest in applying laser welding to aluminum alloys particularly those used for sheet metal processing industries. In other words, laser welding of aluminum alloys, though being investigated for decades, still deserves further investigation as some problems are yet to be solved. This is due to many advantages of laser welding including lowheat input, low distortion, high welding speed, and inherent flexibility of laser system.

The present study was focused on the optimization route and the characterization of laser welds of both AA5000 and AA6000 series aluminum alloys using $\mathrm{CO}_{2}$ laser, which is known to be less efficient for processing of the aluminum alloys in comparison with Nd:YAG laser. In this concern, high-power $\mathrm{CO}_{2}$ laser $(\mathrm{CW})$ with maximum output of $5 \mathrm{~kW}$ power was used. The effect of laser welding parameters such as laser power, welding speed, focal point location, shielding gas flow rate as well as preweld surface cleaning on weld zone configuration, porosity level, and solidification cracking tendency was firstly investigated. Then, the effect of filler metal addition and backing strip on weld quality was clarified. Weld quality was evaluated mainly based on weld zone profile, porosity, solidification cracking, and mechanical properties.

\section{Experimental Procedure}

All materials used in this study are of commercial quality, AA5052 and AA5083 aluminum alloys with $2 \mathrm{~mm}$ thickness and AA6061 aluminum alloy with $2 \mathrm{~mm}$ and $3 \mathrm{~mm}$ thickness. Their chemical compositions and mechanical properties are given in Table 1. A fast axial flow type $\mathrm{CO}_{2}$ laser resonator generating nearly single mode beam (multimode TEM00) with a maximum continuous power of $5 \mathrm{~kW}$ was used. Laser beam was focused to $700 \mu \mathrm{m}$ spot diameter using parabolic mirror system with $200 \mathrm{~mm}$ focal length. Preweld surface cleaning of aluminum alloys was performed using stainless steel wire brush and a nitric acid solution to remove or minimize the surface oxide layer.
The specimens were prepared as square butt joints with machined surfaces and were firmly held using fixture to prevent distortion. Autogeneous, single pass butt welds were made in the transverse direction relative to the rolling direction of samples with $150 \mathrm{~mm}$ length and $100 \mathrm{~mm}$ width (Figure 1). In order to study the effect of backing strip on weld profile and hot cracking of the investigated alloys, backing was applied to some specimens using strips with $2 \mathrm{~mm}, 3 \mathrm{~mm}$ thickness and $50 \mathrm{~mm}$ width from the same base material.

The effect of the filler metal addition on weld profile quality and hot cracking was studied only for AA6061 aluminum alloy. In this regard, AA4043 aluminum filler wire with $1.2 \mathrm{~mm}$ diameter was used since it is recommended as a filler metal for this alloy type.

The laser welding conditions applied are summarized in Table 2. The laser power used was in the range between $3 \mathrm{~kW}$ and $5 \mathrm{~kW}$, while the welding speed was varied between $3 \mathrm{~m} / \mathrm{min}$ and $6 \mathrm{~m} / \mathrm{min}$. The defocusing distance (the distance between the focal point and the specimen surface) was changed between $-4 \mathrm{~mm}$ and $+3 \mathrm{~mm}$. Positive defocusing indicates that the focal point was above the top surface of the workpiece, and negative defocusing indicates that the focal point was below the top surface. The shielding was done using argon gas supplied by a $4 \mathrm{~mm}$ diameter coaxial nozzle with a flow rate ranging between $15 \mathrm{l} / \mathrm{min}$ and $25 \mathrm{l} / \mathrm{min}$.

The quality of the welded specimens was assessed firstly by visual inspection and radiographic test. Then, transverse sections were taken out from all welds and were prepared for mechanical tests (tensile, bending, microhardness) and metallographic examinations. These tests were carried out according to the requirements of American Welding Society, AWS D1.2 Structural Welding Code-Aluminum [20].

The effect of heat treatment on the mechanical properties of welded joints of AA6061 alloy was investigated in samples heated at $200^{\circ} \mathrm{C}$ for 1 hour after welding then, quenched in water.

\section{Results and Discussion}

3.1. Effect of Laser Power and Welding Speed. Regardless of weld appearance, profile and soundness, complete joint penetration at a high welding speed $(5-6 \mathrm{~m} / \mathrm{min})$ was obtained using laser power of $4 \mathrm{~kW}$ for $2 \mathrm{~mm}$ thickness material and $5 \mathrm{~kW}$ for $3 \mathrm{~mm}$ thickness material. For complete penetration using lower laser power, the welding speed was sharply reduced and this, in general, is not acceptable from the view point of productivity. On the other hand, higher laser power with increased welding speed resulted in increasing tendency for solidification cracking.

Photographs of the face and root sides of the alloy AA5083 welded joint made using $4 \mathrm{~kW}$ laser power, $6 \mathrm{~m} / \mathrm{min}$ welding speed, zero defocusing distance, and 151/min argon shielding are shown in Figure 2. Visual examination of all welded joints showed smooth and uniform weld beads free from superficial porosity. However, the most important notice is the existence of remarkable undercut (Figure 2(a)) and excess penetration (Figure 2(b)). This can be clearly observed from macrographs of cross-sections ofthese alloy 
TABLE 1: Chemical composition and mechanical properties of the used aluminum alloys.

(a) Chemical composition (wt \%).

\begin{tabular}{lcccccccc}
\hline Alloy & $\mathrm{Si}$ & $\mathrm{Fe}$ & $\mathrm{Cu}$ & $\mathrm{Mn}$ & $\mathrm{Mg}$ & $\mathrm{Zn}$ & $\mathrm{Cr}$ & $\mathrm{Al}$ \\
\hline AA5052 & 0.09 & 0.19 & 0.08 & 0.07 & 2.55 & 0.01 & 0.19 & bal. \\
AA5083 & 0.12 & 0.20 & 0.09 & 0.57 & 4.61 & 0.03 & 0.12 & bal. \\
AA6061 & 0.65 & 0.31 & 0.27 & 0.12 & 1.05 & 0.01 & 0.25 & bal. \\
\hline
\end{tabular}

(b) Mechanical properties.

\begin{tabular}{lcccc}
\hline Alloy & 0.2\% Proof stress $(\mathrm{MPa})$ & Tensile strength $(\mathrm{MPa})$ & Elongation $(\%)$ & 10 \\
\hline AA5052-H12 & 190 & 230 & 13 & Hardness $(\mathrm{HV})$ \\
AA5083-H12 & 280 & 330 & 13 & 96 \\
AA6061-T6 & 280 & 340 & 96 \\
\hline
\end{tabular}

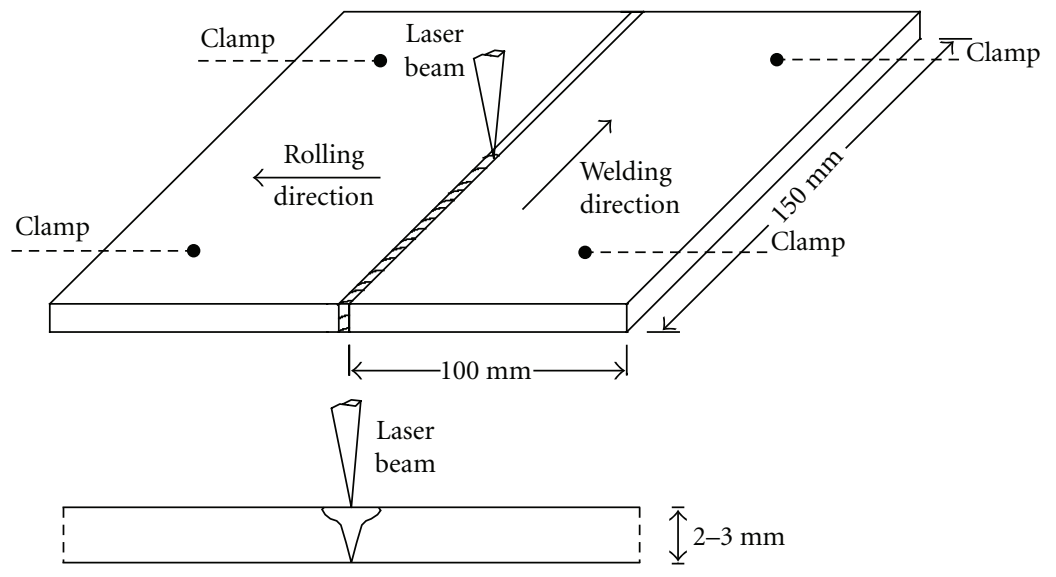

FIGURE 1: Dimensions of laser butt weld joints.

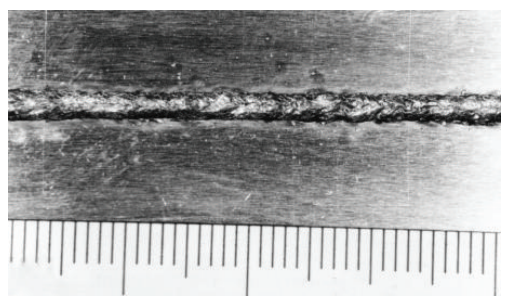

(a)

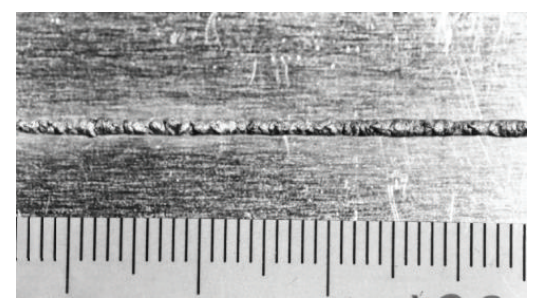

(b)

Figure 2: Face side (a) and root side (b) of alloy AA5083 welded using $\mathrm{P}=4 \mathrm{~kW}, \mathrm{~S}=6 \mathrm{~m} / \mathrm{min}, \mathrm{Dd}=0,15 \mathrm{l} / \mathrm{min}$ argon.

welded joints produced by using different welding speeds as shown in Figure 3. Considerable excess penetration and remarkable underfilling were obtained regardless the range of welding speed. In addition a few amount of small size' porosities was found in the weld metal.

Regarding fusion zone configuration, $4 \mathrm{~m} / \mathrm{min}$ welding speed (Figure 3(a)) resulted in a wide weld bead which is not acceptable in the case of laser welding. Increasing the welding speed to $6 \mathrm{~m} / \mathrm{min}$ (Figure $3(\mathrm{~b})$ ) resulted in a typical laser weld shape where remarkable decrease in the weld bead width was obtained. However, the encountered problem in this case is the existence of weld metal solidification cracking. It should be reported that similar results regarding fusion zone configuration, porosity and cracking of weld metal were obtained for the other nonheat treatable AA5052 and heat treatable AA6061 alloys. Weld metal solidification cracking was observed with increasing the welding speed to $4 \mathrm{~m} / \mathrm{min}$ in the case of AA6061 alloy as shown in Figure 4.

Concerning porosity, it is thought to be caused by the vaporization of volatile alloying elements, where magnesium can vaporize at relatively low temperature, which may result in unacceptable porosity in laser welds [21]. However, energy dispersive X-ray (EDX) microanalysis of all the investigated alloys indicated no significant difference in $\mathrm{Mg}$ and $\mathrm{Si}$ contents in both base and weld metals as shown in Figure 5 for alloy AA5083. This is related to careful control of the process parameters. Consequently, it was assumed that the porosity present in the weld metal could be attributed to 


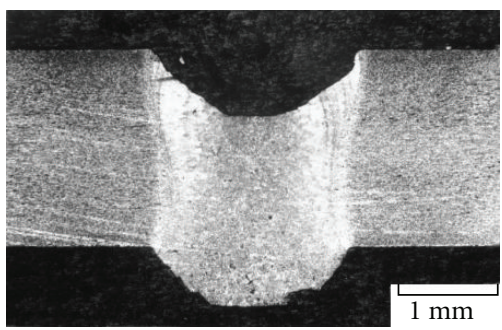

(a)

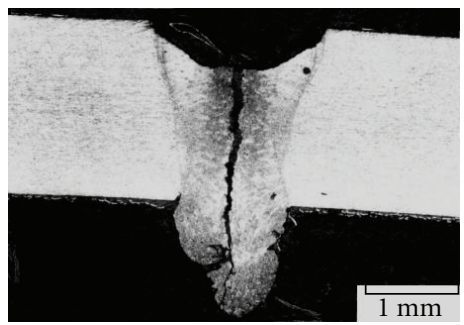

(b)

FIGURE 3: Fusion zone configuration of alloy AA5083 made using $\mathrm{P}$ $=4 \mathrm{~kW}, \mathrm{Dd}=0,15 \mathrm{l} / \mathrm{min}$ argon. (a) $\mathrm{S}=4 \mathrm{~m} / \mathrm{min}$, (b) $\mathrm{S}=6 \mathrm{~m} / \mathrm{min}$.

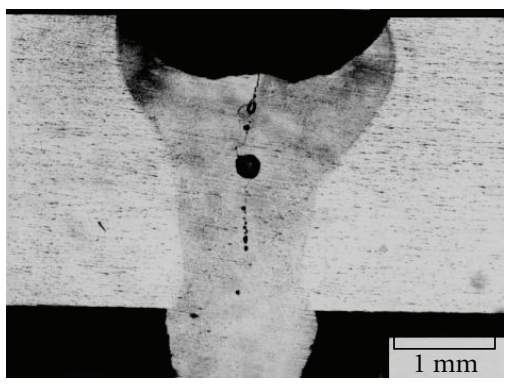

Figure 4: Fusion zone configuration of alloy AA6061 made using $\mathrm{P}$ $=5 \mathrm{~kW}, \mathrm{~S}=4 \mathrm{~m} / \mathrm{min}, \mathrm{Dd}=0,15 \mathrm{l} / \mathrm{min}$ argon.

surface contamination of the parent metal with hydroxides, hydrocarbons, and, to a lesser extent, insufficient shielding. It is well reported that the major cause for porosity formation in aluminum alloys is the hydrogen incorporation in the liquid, and even 2 ppm of hydrogen in the liquid can be sufficient to produce porosity in aluminum welds [22]. This is related to significant hydrogen solubility difference in both liquid and solid alloy where hydrogen solubility in liquid is much higher than that in solid. In other words, the hydrogen porosityis formed as a result of rejection of hydrogen from the solid due to reduced solubility $[23,24]$.

In the present investigation, it is believed that porosity formation was mainly attributed to insufficient surface cleaning of base metal prior to welding and, to a lesser extent, insufficient shielding. Then, porosity level was remarkably reduced by careful mechanical and chemical cleaning of base metal prior to welding and by increasing the flow rate of shielding gas to $25 \mathrm{l} / \mathrm{min}$. This means that the levels of porosity in the welds are dependent on the laser welding procedure where both preweld surface cleaning and optimized gas shielding can be effective.

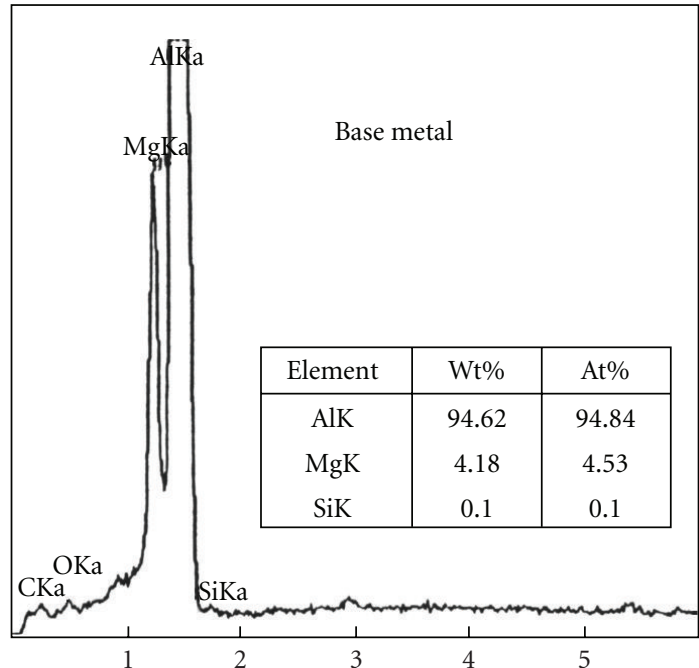

(a)

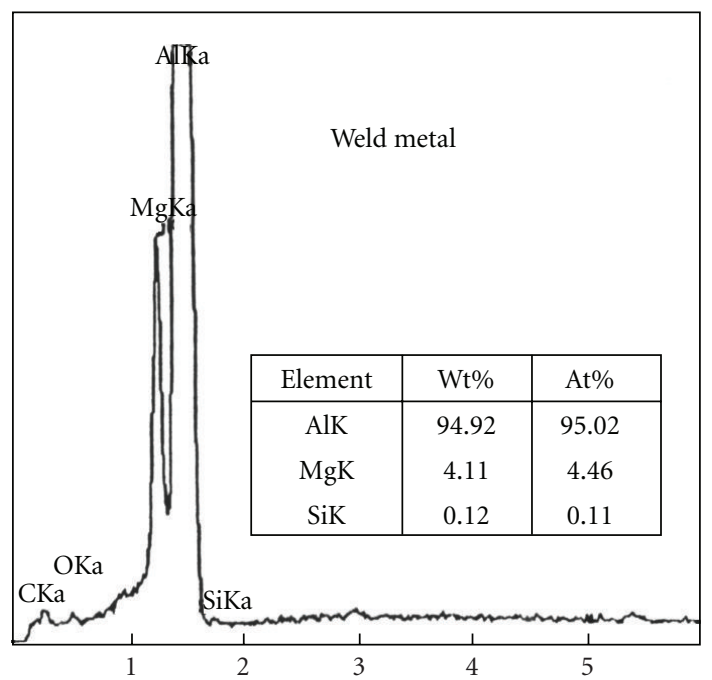

(b)

FIGURE 5: EDX microanalysis of base metal (a) and weld metal (b) of alloy AA5083 welded joint.

Besides, it is believed that cleaning of the workpiece surface prior to welding using a stainless steel brush and a nitric acid solution has resulted in increasing surface roughness and subsequently decreasing surface reflectivity that means enhancing the laser energy coupling during welding. This could be a practical solution to reduce reflectivity and then improve efficiency of the $\mathrm{CO}_{2}$ laser, which is known to be lower than that of the Nd:YAG laser for the welding of aluminum alloys.

For all the investigated alloys, cracking was observed only in weld metal while HAZ was free from cracking. Table 3 shows the weld crack occurrence in these alloys at different welding speeds. Cracks were found in AA5052 and AA5083 alloys at more than $4 \mathrm{~m} / \mathrm{min}$ welding speed and in AA6061 alloy at more than $3 \mathrm{~m} / \mathrm{min}$ welding speed. 
TABLE 2: Laser welding parameters.

\begin{tabular}{lcccr}
\hline Thickness $(\mathrm{mm})$ & $\mathrm{P}(\mathrm{kW})$ & $\mathrm{S}(\mathrm{m} / \mathrm{min})$ & Dd $(\mathrm{mm})$ & Shielding gas/ flow rate $(\mathrm{L} / \mathrm{min})$ \\
\hline 2 & $3 \sim 5$ & $3 \sim 6$ & $-4.0 \sim+3.0$ & Argon/15 25 \\
3 & $4 \sim 5$ & $3 \sim 6$ & $-4.0 \sim+3.0$ & Argon/15 $\sim 25$ \\
\hline
\end{tabular}

P: Power, S: Speed, Dd: Defocusing distance.

TABLE 3: Effect of welding speed on cracking of welded joints made without backing strip.

\begin{tabular}{lllll}
\hline \multirow{2}{*}{ Alloy } & & \multicolumn{3}{c}{ Welding speed $\mathrm{mm} / \mathrm{min}$} \\
& 3 & 4 & 5 & $\mathrm{X}$ \\
$\mathrm{AA5052}$ & $\mathrm{O}$ & $\mathrm{O}$ & $\mathrm{X}$ & $\mathrm{X}$ \\
AA5083 & $\mathrm{O}$ & $\mathrm{O}$ & $\mathrm{X}$ & $\mathrm{X}$ \\
AA6061 & $\mathrm{O}$ & $\mathrm{X}$ & \\
\hline
\end{tabular}

O No weld crack, X Weld crack exist.

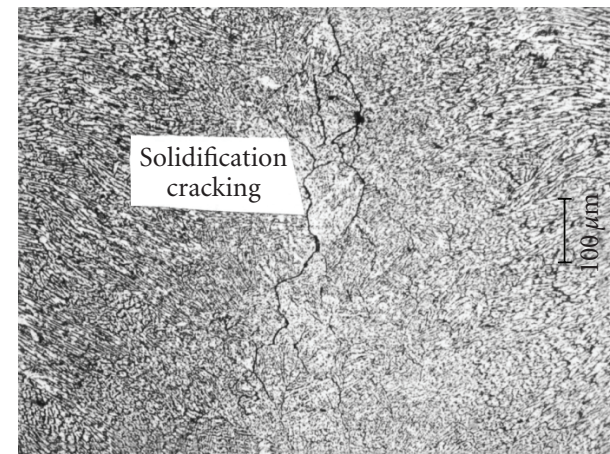

FIGURE 6: Optical micrograph of weld metal of AA6061 joint made using $\mathrm{P}=5 \mathrm{~kW}, \mathrm{~S}=4 \mathrm{~m} / \mathrm{min}, \mathrm{Dd}=0,15 \mathrm{l} / \mathrm{min}$ argon.

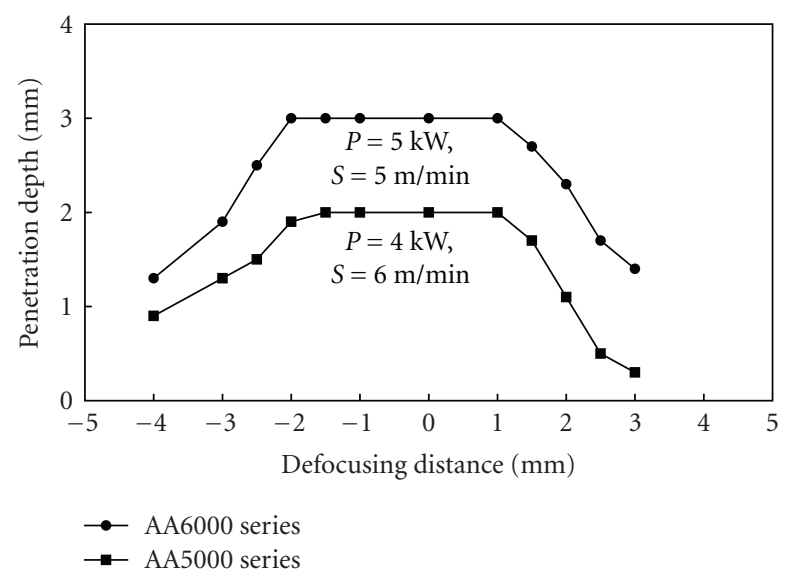

Figure 7: Penetration depth as a function of defocusing distance for the investigated aluminum alloys.

Optical microscopic examinations of the weld metal of all investigated alloys revealed a cellular dendritic structure with an equiaxed zone formation along the centerline of the weld as shown in Figure 6 for AA6061 alloy. Cracks were observed along the boundaries of equiaxed zone formed along the weld centerline, and they were confirmed to be solidification cracks.

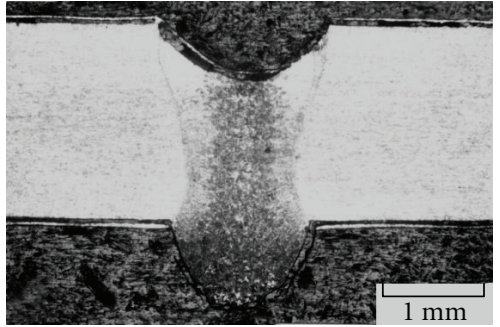

(a)

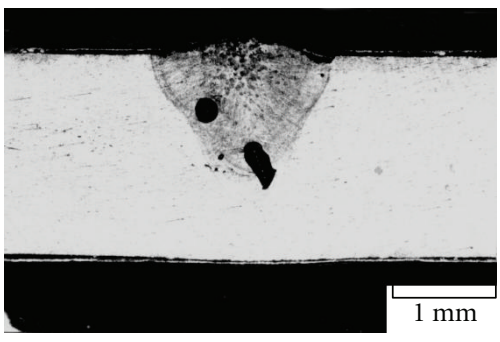

(b)

Figure 8: Fusion zone configuration of alloy AA5083 made using $\mathrm{P}$ $=4 \mathrm{~kW}, \mathrm{~S}=6 \mathrm{~m} / \mathrm{min}$. (a) Dd $=-1.5 \mathrm{~mm}$, (b) Dd $=-3 \mathrm{~mm}$.

Generally, weld cracking in aluminum alloys can occur as a result of the aluminum relative high thermal expansion, large change in volume upon solidification, and wide solidification temperature range. The investigated AA5052, AA5083, and AA6061 alloys are known to be highly susceptible to weld cracks also in other conventional welding processes [25]. The mechanism of crack occurrence in the laser welding is considered to be similar to that of the arc welding. However, severity of weld metal cracking in the case of laser welding is much less than that in the case of arc welding due to the lower heat input with laser welding [26]. It is believed that the solidification cracking problem in this investigation is attributed to high stress concentration at the center of weld bead due to its concavity and its high depth/width ratio as a result of unacceptable excess penetration. 


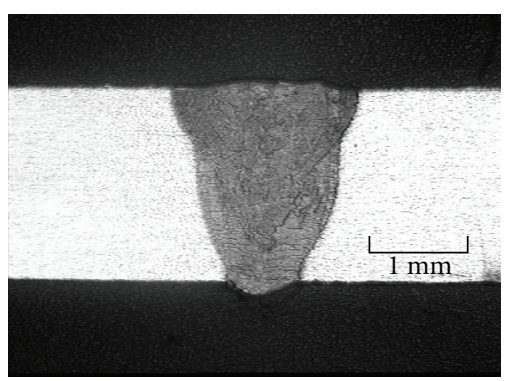

Figure 9: Cross section of AA6061 butt welded joint produced using $\mathrm{P}=4 \mathrm{~kW}, \mathrm{~S}=6 \mathrm{~m} / \mathrm{min}, \mathrm{Dd}=-1.5 \mathrm{~mm}$ with filler wire.

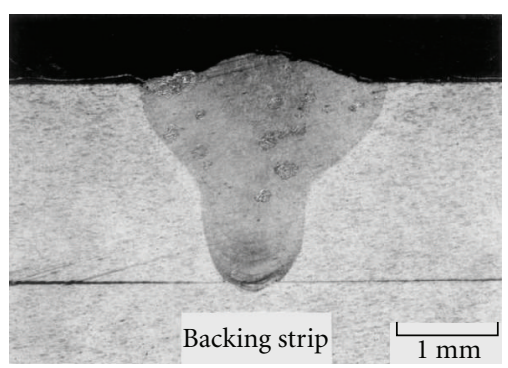

(a)

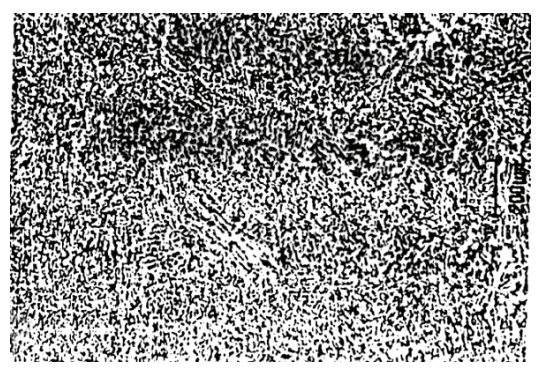

(b)

Figure 10: (a) Cross section of AA5083 butt welded joint produced using backing strip with $\mathrm{P}=4 \mathrm{~kW}, \mathrm{~S}=6 \mathrm{~m} / \mathrm{min}, \mathrm{Dd}=-1.5 \mathrm{~mm}$, (b) Optical micrograph of its weld metal.

3.2. Effect of Defocusing Distance. In the previous section, the focal point was adjusted to be at the top surface of the specimen which means zero defocusing distance. In order to clarify its effect on both penetration depth and fusion zone configuration, the defocusing distance was varied between -4 and $+3 \mathrm{~mm}$. Figure 7 shows the penetration depth as a function of the defocusing distance using $4 \mathrm{~kW}, 6 \mathrm{~m} / \mathrm{min}$ for $2 \mathrm{~mm}$ thickness and $5 \mathrm{~kW}, 5 \mathrm{~m} / \mathrm{min}$ for $3 \mathrm{~mm}$ thickness aluminum alloy sheets. Complete penetration for both 2 and $3 \mathrm{~mm}$ thickness joints was obtained at a wide range of the defocusing distance $(-1.5$ and $+1 \mathrm{~mm})$. However, acceptable weld profile was obtained with shifting the focal point below the specimen' top surface. Increasing or decreasing the defocusing distance out of this range resulted in a remarkable decrease in the penetration depth. This is due to the sharp decrease in the laser beam power density at the specimen' top surface in both cases.

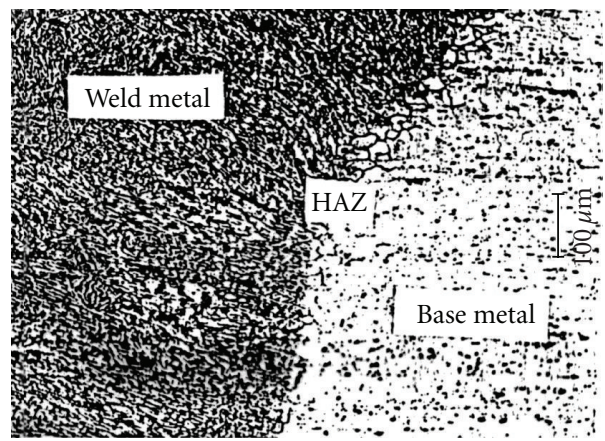

FIGURE 11: Optical micrograph of fusion boundary of AA6061 butt welded joint produced using $\mathrm{P}=5 \mathrm{~kW}, \mathrm{~S}=4 \mathrm{~m} / \mathrm{min}, \mathrm{Dd}=-1.5 \mathrm{~mm}$, 251/min argon.

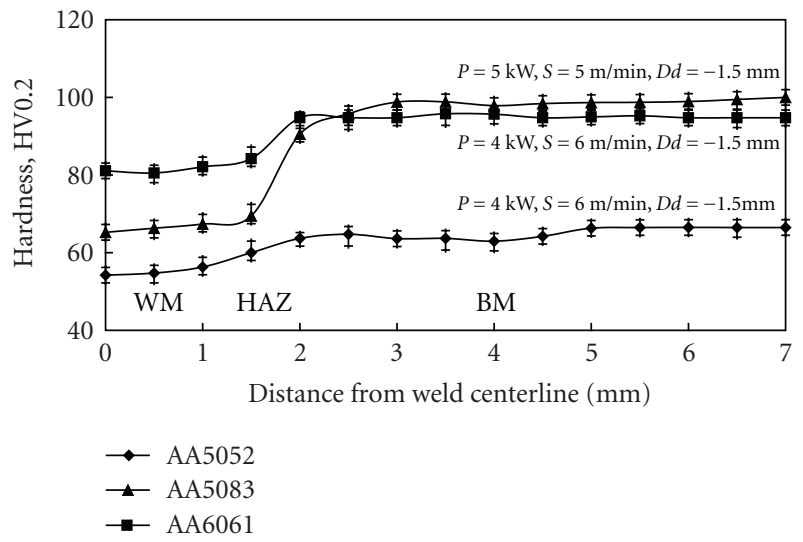

Figure 12: Hardness profiles through weld metal, HAZ, and base metal $\mathrm{f}$ both AA5000 and AA6000 series alloys.

Typical fusion zone configuration of AA5083 aluminum alloy welded using $4 \mathrm{~kW}$ laser power and $6 \mathrm{~m} / \mathrm{min}$ welding speed at two different defocusing distancesis shown in Figure 8. It can be noticed that shifting the focal point $3 \mathrm{~mm}$ below the specimen' top surface (Figure $8(\mathrm{~b})$ ) resulted in forming large size porosity and decreasing the penetration depth to about half of its value obtained at $-1.5 \mathrm{~mm}$ defocusing distance (Figure 8(a)). However, the problem is still concerned with weld solidification cracking in the case of $-1.5 \mathrm{~mm}$ defocusing distance as has been observed through optical microscopic examination of weld metal.

It is believed that this problem could be related to two main reasons. Firstly, the high depth/width ratio due to a remarkable excess penetration (Figure $8(a)$ ), which could increase the welding residual stresses acting on the weld bead in a perpendicular direction. Secondly, the concave shape of the weld face (Figure 8(a)) that could result in high stress concentration at the center of the weld bead, in comparison with the convex weld shape (Figure 8(b)).

3.3. Effect of Filler Wire and Backing Strip. Results of the previous sections revealed that the optimum laser parameters concerning complete penetration with narrow fusion zone free from porosity were $4 \mathrm{~kW}, 6 \mathrm{~m} / \mathrm{min},-1.5 \mathrm{~mm}$ for $2 \mathrm{~mm}$ 


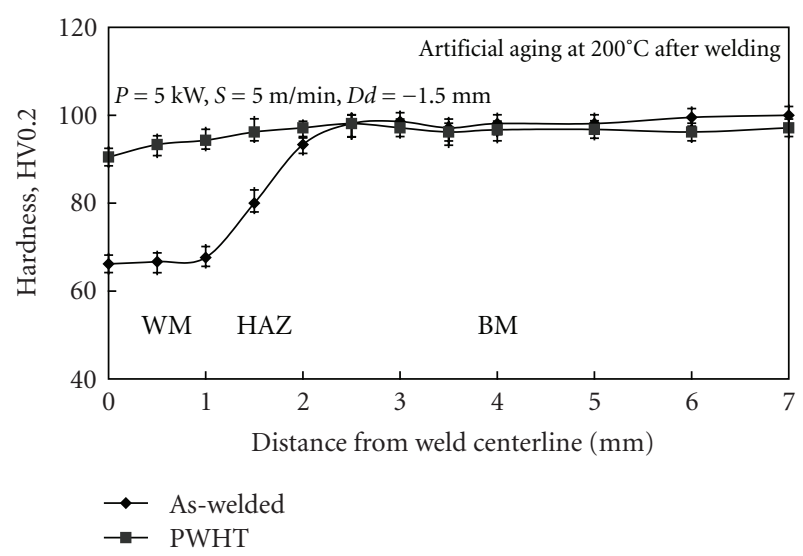

FIgURE 13: Effect of artificial aging at $200^{\circ} \mathrm{C}$ after welding on hardness of alloy AA6061 welded joint.

thickness material and $5 \mathrm{~kW}, 5 \mathrm{~m} / \mathrm{min},-1.5 \mathrm{~mm}$ for $3 \mathrm{~mm}$ thickness material. However, it is confirmed that the investigated aluminum alloys were susceptible to solidification cracking even under these optimum welding parameters. This solidification cracking problem has been solved in this study using two different approaches. The first one was based on adding a filler wire instead of the autogeneous welding, where acceptable laser weld profile free from solidification cracking was obtained as shown in Figure 9. This result is in a good agreement with other research works as has been demonstrated in some studies on AA5000 and AA6000 series alloys [27].

The other approach was concerned with solving the solidification cracking problem in autogeneous welding using a backing strip from the same base metal. Visual examination of welded joints produced using this technique revealed smooth and uniform weld beads where undercut and excess penetration were remarkably reduced to an acceptable limit that in turn eliminated solidification cracking. It should be reported that the same parameters were used for welds produced using either a backing strip or a filler wire. In other words, the welding speed or the productivity was not decreased with the addition of the filler fire.

A cross section taken from laser welded joint of AA5083 alloy produced using the optimum welding parameters and a backing strip is shown in Figure 10(a). It is obvious that using a backing strip resulted in remarkable improvement in weld bead shape, where it became convex, the recommended and acceptable shape concerning hot cracking. Besides, the root penetration was limited to the required and acceptable limit. Another important finding is the absence of weld metal solidification cracking in this case. This has been confirmed from optical microscopic examination of weld metal at higher magnification as shown in Figure 10(b). This is attributed to the decrease in stress concentration at the center of weld bead due to improving the weld profile, that is, obtaining a convex bead and decreasing penetration depth/width ratio. It should be reported that similar results regarding the effect of the backing strip on

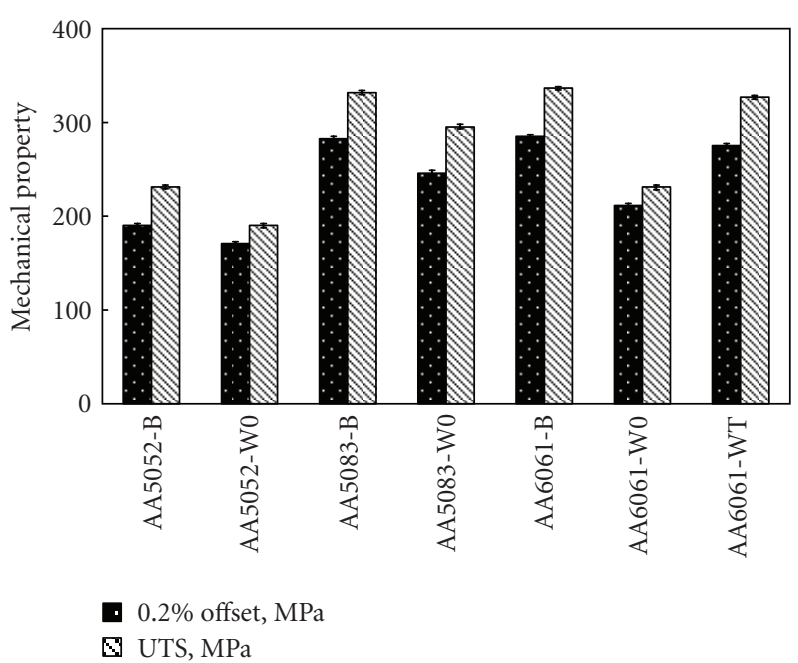

FIGURE 14: $0.2 \%$ proof stress and tensile strength of welded joints of AA5052, AA5083, and AA6061 alloys together with those of base metals. B: Base metal, W0: As-welded, WT: Heat treated; aged after welding.

the weld profile and then on the weld solidification cracking were obtained for both AA5052 and AA6061 alloys. It can be deduced that using a backing strip could be a new and relatively inexpensive practical solution for preventing the solidification cracking of aluminum alloys welded joints. Other researchers have eliminated the solidification cracking problem in aluminum alloys using temporal pulse shaping [28].

Figure 11 shows optical micrograph of a cross section taken from fusion boundary of AA6061 butt welded joint, produced using $5 \mathrm{~kW}, 4 \mathrm{~m} / \mathrm{min},-1.5 \mathrm{~mm}$, and $25 \mathrm{l} / \mathrm{min}$ argon. The most noticeable feature is the narrow HAZ width. This is related mainly to low-heat input that resulted in narrow weld zone and subsequently narrow HAZ.

3.4. Mechanical Properties. Microhardness profiles through weld metal, HAZ, and base metal of all alloys studied are shown in Figure 12. Weld metal width of both AA5000 and AA6000 series alloys is about $2 \mathrm{~mm}$ while their HAZ width is about $1 \mathrm{~mm}$. For the three investigated alloys, the lowest hardness value was obtained at the weld metal then, the hardness was increased gradually in the HAZ until it became almost equal to that of the base metal. It can be noticed also that the highest decrease in hardness and the wider soft zone due to welding among the three investigated alloys were attained in the case of AA6061 alloy. However, such softening can be recovered by a postweld aging treatment. Figure 13 shows the effect of artificial aging at $200^{\circ} \mathrm{C}$ after welding on the hardness of welded joint of this alloy. It is clear that the hardness of both weld metal and HAZ was significantly increased by the postweld aging treatment, where it became close to that of the base metal.

Both $0.2 \%$ proof stress and tensile strength of welded joints of AA5052, AA5083, and AA6061 alloys are shown in Figure 14, while their tensile elongation is shown in 


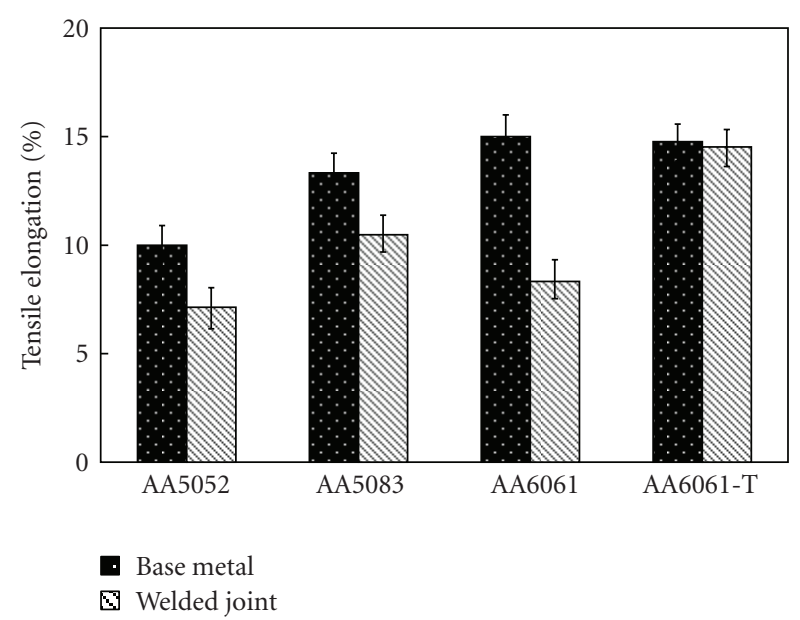

Figure 15: Tensile elongation of welded joints of AA5052, AA5083, and AA6061 alloys together with that of base metals. T: Heat treated; aged after welding.

Figure 15. In comparison with mechanical properties of the base metal, welding has resulted in deterioration of $0.2 \%$ proof stress, tensile strength (Figure 14), and elongation (Figure 15) of the three investigated alloys. However, the deterioration was severe in the case of AA6061 alloy. 0.2\% proof stress and tensile strength of both AA5052 and AA5083 welded joints were reduced to about $87 \%$, while their elongation was reduced to about $75 \%$ of those of the base metal where all the samples failed in the weld metal. For AA6061 alloy, $0.2 \%$ proof stress and tensile strength of aswelded joint were remarkably decreased to about $65 \%$ while its elongation was reduced to about $55 \%$ of those of the base metal, with the samples again failing in the weld metal. After post-weld aging treatment at $200^{\circ} \mathrm{C}$, both tensile strength (Figure 14) and elongation (Figure 15) were increased to about $97 \%$ of those of the base metal. These improvements in the mechanical properties of postweld aged specimens are attributed to the reprecipitationpitation of strengthening precipitates particles of $\mathrm{Mg}_{2} \mathrm{Si}$ in both weld metal and HAZ.

It is clear that the same levels of tensile strength and elongation of the base metal could not be achieved for welded joints. For both AA5052 and AA5083 alloys, the materials were supplied in the $\mathrm{H} 12$ work hardened conditions. Reheating such work hardened material above $350^{\circ} \mathrm{C}$ will cause a decrease in strength due to the recrystallization of the material [29]. On the other hand, AA6061 alloy was supplied in the T6 temper condition, solution heat treated and artificially aged. Then, the welding heat will cause dissolution of the strengthening precipitates $\left(\mathrm{Mg}_{2} \mathrm{Si}\right)$ leading to dramatic softening.

Generally, in order to maintain the mechanical properties when welding aluminum alloys, the heat input and time of exposure to very high temperatures must be minimized. In comparison with arc welding processes, laser welding offers the benefits of low-heat input and extremely rapid cooling rate, all of which will help to minimize the metallurgical problems in the fusion zone. For example, high cooling rate will tend to slow down the development of blisters because of the short time in which the diffusion of hydrogen can take place. In addition, the low-heat input will tend to keep a very narrow HAZ then, retaining some to the strength of the material. Even though electron beam welding offers the advantages of a high energy density welding process, a vacuum chamber is required, which is not always practical.

\section{Conclusions}

In view of the results achieved in this study, the following conclusions can be obtained.

(1) The use of high-power intensity focused $\mathrm{CO}_{2}$ laser beam with optimized parameters and careful material preparation prior to welding can produce welds with high quality for both AA5000 and AA6000 series alloys. Welding speed of $6 \mathrm{~m} / \mathrm{min}$ and laser power of $4 \mathrm{~kW}$ have resulted in full penetration of $2 \mathrm{~mm}$ thickness welded joint while $5 \mathrm{~m} / \mathrm{min}$ and $5 \mathrm{~kW}$ have resulted in full penetration of $3 \mathrm{~mm}$ thickness welded joint. Optimum weld profile was obtained when focal point was placed $1.5 \mathrm{~mm}$ below the specimen top surface. It is believed that the efficiency of $\mathrm{CO}_{2}$ laser beam welding of aluminum alloys could be improved by cleaning the workpiece surface prior to welding using a stainless steel brush and a nitric acid solution. This is due to increasing surface roughness that means decreasing surface reflectivity and enhancing the laser energy coupling during welding.

(2) All the investigated alloys showed tendencies for porosity and solidification cracking particularly, at high welding speed ( $\geq 4 \mathrm{~m} / \mathrm{min}$ ). Porosity was prevented by accurate cleaning of the base metal before welding and optimizing the flow rate of argon shielding gas. Solidification cracking problem has been solved through two different approaches. The first one was based on the addition of filler metal as reported in other research works. The other new approach was concerned with performing autogeneous welding with a backing strip from the same base metal, and this could be applicable in production.

Preventing solidification cracking in both cases was related mainly to a remarkable decrease in the stress concentration at the weld metal center due to improving fusion zone profile, decrease in excess penetration, and subsequently decrease in fusion zone depth/width ratio together with a convex weld bead instead of a concave one.

The implementation of the new approach could help in improving the quality due to the absence of filler metal, which is known as a source for hydrogen-related porosity. It can also have a positive economic aspect regarding the manufacturing cost as a result of autogeneous welding. Not only quality and economic positive aspects could be achieved in this case, but also high productivity is another feature since high quality autogeneous weldments were produced with high welding speed, $6 \mathrm{~m} / \mathrm{min}$.

(3) In comparison with alloys AA5052 and AA5083 as work hardenable materials, AA6061 alloy as aged hardened material has experienced severe deterioration in mechanical properties due to softening in the fusion zone resulting from dissolution of the strengthening precipitates in the weld metal and HAZ. However, such deterioration has been 
recovered by postweld aging treatment, which has resulted in a significant improvement in the mechanical properties.

\section{Acknowledgments}

The authors would like to acknowledge Laser X Co. Ltd., Japan for conducting laser beam welding. The authors are indebted to Professor A. N. Abdel-Azim, Non-Ferrous Alloys Laboratory, and Professor A. Nofal, Foundry Technology Laboratory at Central Metallurgical R \& D Institute, Cairo for their valuable and fruitful discussion and assistance.

\section{References}

[1] K. R. Brown, M. S. Venie, and R. A. Woods, "The increasing use of aluminum in automotive applications," Journal of Metals, vol. 47, no. 7, pp. 20-23, 1995.

[2] G. D. Howden, "An up-to-date look at porosity formation in aluminum weldments," Welding Journal, vol. 50, no. 1, 1971.

[3] M. H. Scott and M. F. Gittos, "Tensile and toughness properties of Arc-welded 5083 and 6082 aluminum alloys," Welding Journal, vol. 62, no. 9, pp. 243s-252s, 1983.

[4] B. Zaghloul, W. Metwally, A. El-Batahgy, and M. Mosalam, "A study on hot cracking and corrosion susceptibility of some aluminum alloys weldments," in Proceedings of the 6th Arab International Aluminum Conference (ARABAL '93), Cairo, Egypt, December 1993.

[5] F. Matsuda and K. Nakata, "Evaluation of ductility characteristics and cracking susceptibility of $\mathrm{Al}$ alloys during welding," Transactions of JWRI, vol. 24, no. 1, pp. 83-94, 1995.

[6] W. van Haver, X. Stassart, J. Verwimp, B. De Meester, and A. Dhooge, "Friction stir welding and hybrid laser welding applied to 6056 alloy," Welding in the World, vol. 50, no. 1112, pp. 65-77, 2006.

[7] U. Dilthey, A. Brandenburg, and F. Reich, "Investigation of the strength and quality of aluminium laser-mig-hybrid welded joints," Welding in the World, vol. 50, no. 7-8, pp. 7-10, 2006.

[8] F. S. Bayraktar and P. S. Staron, "Residual stress analysis of laser welded aluminum $\mathrm{T}$ joints using neutron diffraction," Welding in the World, vol. 51, no. 1-2, pp. 28-34, 2007.

[9] J. Mazumder, "Laser welding: state of the art review," Journal of Metals, vol. 34, no. 7, pp. 16-24, 1982.

[10] T. Mars, Mass transfer studies of laser welded aluminum alloys 5083 and 7039, M.S. thesis, Department of Materials Science and Engineering, PSU, University Park, Pa, USA, 1988.

[11] D. W. Moon and E. A. Metzbower, "Laser beam welding of aluminum alloy 5456," Welding Journal, vol. 62, no. 2, pp. 53s$58 \mathrm{~s}, 1983$.

[12] H. Zhao, D. R. White, and T. DebRoy, "Current issues and problems in laser welding of automotive aluminum alloys," International Materials Reviews, vol. 44, no. 6, pp. 238-266, 1999.

[13] W. W. Duley, Laser Processing and Analysis of Materials, Plenum Press, New York, NY, USA, 1983.

[14] M. Kutsuna, S. Kitamura, K. Shibata, H. Sakamoto, and K. Tsushima, "Improvement of the joint performance in laser welding of aluminium alloys," Welding in the World, vol. 50, no. 1-2, pp. 22-27, 2006.

[15] J. Rapp, C. Glumann, F. Dausinger, and H. Hügel, "Laser welding of aluminium lightweight materials: problems, solutions, readiness for application," Optical and Quantum Electronics, vol. 27, no. 12, pp. 1203-1211, 1995.
[16] M. Pastor, H. Zhao, R. P. Martukanitz, and T. DebRoy, "Porosity, underfill and magnesium loss during continuous wave Nd:YAG laser welding of thin plates of aluminum alloys 5182 and 5754," Welding Journal, vol. 78, no. 6, pp. 207s-216s, 1999.

[17] H. Zhao and T. DebRoy, "Weld metal composition change during conduction mode laser welding of aluminum alloy 5182," Metallurgical and Materials Transactions B, vol. 32, no. 1, pp. 163-172, 2001.

[18] J. Xie, "Dual beam laser welding," Welding Journal, vol. 81, no. 10, pp. 223s-230s, 2002.

[19] H. Zhao and T. DebRoy, "Macroporosity free aluminum alloy weldments through numerical simulation of keyhole mode laser welding," Journal of Applied Physics, vol. 93, no. 12, pp. 10089-10096, 2003.

[20] American Welding Society AWS D1.2 Structural Welding Code-Aluminum, 1992.

[21] S. Mukae, M. Katou, K. Kasuga, and H. Ichikawa, "Improving the softened zone in welds in A5083-H aluminum alloy," Welding International, vol. 6, no. 10, pp. 774-779, 1992.

[22] D. R. Askeland, The Science and Engineering of Materials, PWS, Boston, Mass, USA, 1985.

[23] T. A. Marsico and R. Kossowsky, "Laser beam welding of aluminum alloy plates 7039, 5083, and 2090," in Proceeding of the International Congress on Applications of Lasers and ElectroOptics (ICALEO '89), pp. 61-71, 1989.

[24] H. Matsumura, T. Orihashi, S. Nakayama, et al., " $\mathrm{CO}_{2}$ laser welding characteristics of various aluminum alloys," in Proceedings of LAMP, pp. 529-533, 1992, Nagaoka, Japan.

[25] M. Kutsuna, J. Suzuki, S. Kimura, S. Sugiyama, M. Yuhki, and H. Yamaoka, " $\mathrm{CO}_{2}$ laser welding of A2219, A5083 and A6063 aluminium alloys," Welding in the World, vol. 31, no. 2, pp. 126-135, 1993.

[26] R. A. Woods, "Porosity and hydrogen adsorption in aluminum welds," Welding Journal, vol. 53, no. 3, 1974.

[27] Y. Arata, N. Abe, and T. Oda, "Laser welding of aluminum and aluminum alloys," Transactions of JWRI, vol. 16, pp. 423-425, 1987.

[28] J. Zhang, D. C. Weckman, and Y. Zhou, "Effects of temporal pulse shaping on cracking susceptibility of 6061-T6 aluminum Nd:YAG laser welds," Welding Journal, vol. 87, no. 1, pp. 18s30s, 2008.

[29] I. Masumoto, M. Kutsuna, and J. Suzuki, "Laser welding of A5083 aluminum alloy," in Proceedings of the Annual Assembly of International Institute of Welding, The Hague, The Netherlands, July 1991, IIW Document IV-566-91. 

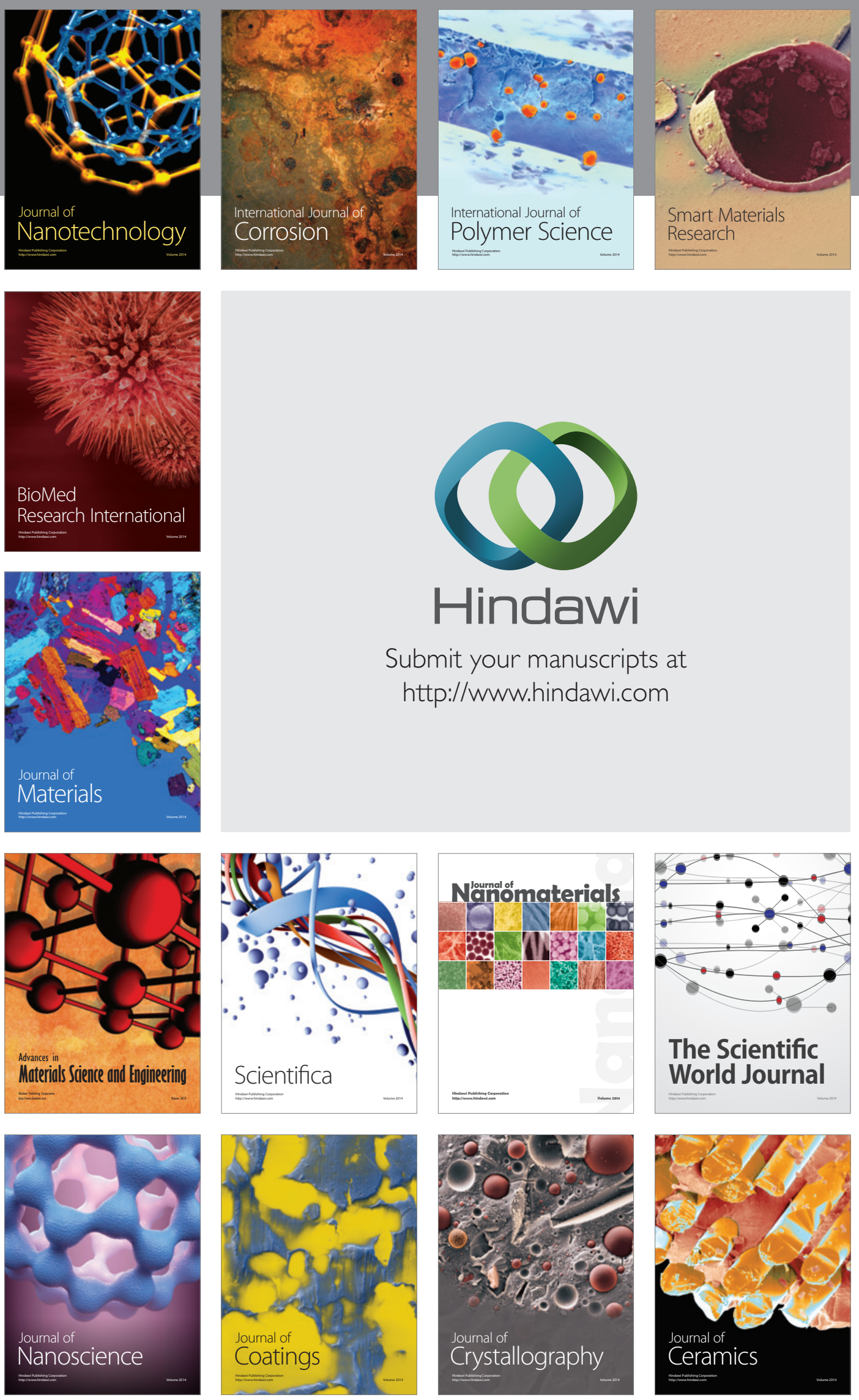

The Scientific World Journal

Submit your manuscripts at

http://www.hindawi.com

\section{World Journal}

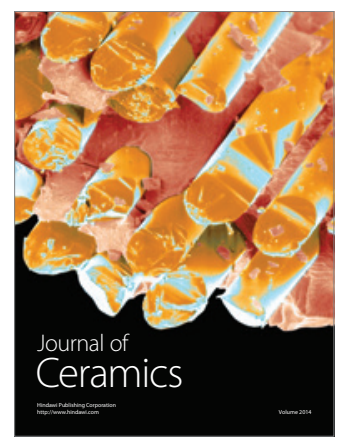

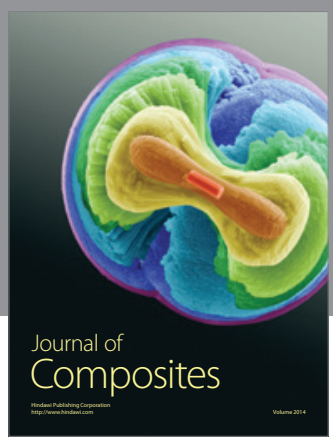
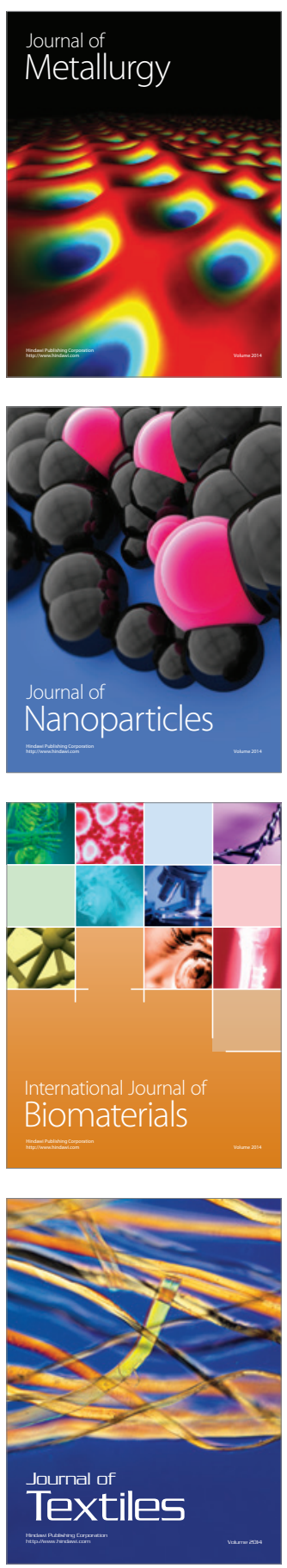